\title{
Does MPA mean 'Major Problem for Assessments'? Considering the consequences of place-based management systems
}

\author{
John C. Field ${ }^{1 *}$, André E. Punt ${ }^{2}$, Richard D. Methot ${ }^{3}$ E Cynthia J. Thomson ${ }^{1}$ \\ ${ }^{1}$ Fisheries Ecology Division, Southwest Fisheries Science Center, NOAA Fisheries, 110 Shaffer Rd., Santa Cruz, CA 95062, \\ USA; ${ }^{2}$ School of Aquatic and Fishery Sciences, University of Washington, Seattle, WA 98195-5020, USA; ${ }^{3}$ Office of Science \\ and Technology, NOAA Fisheries, 2725 Montlake Blvd. E, Seattle, WA 98112, USA
}

\begin{abstract}
Marine protected areas (MPAs) have been increasingly proposed, evaluated and implemented as management tools for achieving both fisheries and conservation objectives in aquatic ecosystems. However, there is a challenge associated with the application of MPAs in marine resource management with respect to the consequences to traditional systems of monitoring and managing fisheries resources. The place-based paradigm of MPAs can complicate the population-based paradigm of most fisheries stock assessments. In this review, we identify the potential complications that could result from both existing and future MPAs to the science and management systems currently in place for meeting conventional fisheries management objectives. The intent is not to evaluate the effects of implementing MPAs on fisheries yields, or even to consider the extent to which MPAs may achieve conservation oriented objectives, but rather to evaluate the consequences of MPA implementation on the ability to monitor and assess fishery resources consistent with existing methods and legislative mandates. Although examples are drawn primarily from groundfish fisheries on the West Coast of the USA, the lessons are broadly applicable to management systems worldwide, particularly those in which there exists the institutional infrastructure for managing resources based on quantitative assessments of resource status and productivity.
\end{abstract}

Keywords fisheries assessment, fisheries management, fish stock, marine protected area, spatial model

\author{
"Correspondence: \\ John C. Field, Fisher- \\ ies Ecology Division, \\ Southwest Fisheries \\ Science Center, \\ NOAA Fisheries, 110 \\ Shaffer Rd., Santa \\ Cruz, CA 95062, USA \\ Tel.: + 1-831-420- \\ 3907 \\ Fax: + 1-831-420- \\ 3977 \\ E-mail: john.field@ \\ noaa.gov
}

Received 26 May 2006

Accepted 15 Aug 2006 


\section{Introduction}

The application of marine protected areas (MPAs ${ }^{1}$ ) and other spatially based management efforts (such as rotating closures and ocean zoning) has been increasingly accepted as a feasible tool for marine resource management (Murray et al. 1999; Murawski et al. 2000; Roberts et al. 2001; Pikitch et al. 2004). For example, a National Research Council (NRC) panel found 'compelling empirical evidence and strong theoretical arguments' for the use of MPAs and marine reserves as tools for managing fisheries, protecting habitat and biodiversity, and enhancing the anthropocentric value (esthetic and otherwise) of marine habitat (NRC 2001). As management tools, MPAs potentially offer a form of insurance against (a) overexploitation of target species, (b) the compression of the age structure of fished populations, (c) undesirable fishinginduced impacts on non-target species, (d) reduction in biodiversity and (e) fishing-induced impacts to habitat (NRC 2001; Gerber et al. 2003; Halpern 2003). Consequently, there is widespread consensus that MPAs are appropriate tools for achieving conservation needs that may be difficult to achieve under stock-wide or fishery-wide management approaches.

Marine protected areas are, however, not a panacea for solving marine resource management problems, and the effect of MPAs on yield remains a critical issue. As Botsford et al. (2004) discuss, fishing is typically the primary action being limited so the effects of MPAs on yield are central to any policy decisions regarding MPA implementation. Mangel (1998) and Botsford et al. (2004) have shown that, in the absence of detailed information regarding larval transport and benthic productivity, it is

\footnotetext{
${ }^{1}$ Throughout this paper we will use the term 'MPA' to mean an area with legal boundaries in which fishing is prohibited for all or a subset of species, or particular fishing gears are disallowed with some degree of permanence (excluding spatial management measures that are more dynamic in nature). According to this definition, 'marine reserves' are a type of MPA in which all fishing is disallowed.
}

possible to show a rough equivalence between the yield of a single species that is possible with reserves and with conventional management techniques, such that reserves can function roughly equivalent to reducing effort in a fishery. However, MPAs more typically reduce the maximum potential yield because fish in the MPA do not directly contribute to this yield (Mangel 1998; SladekNowlis and Roberts 1999), although exceptions to this generalization are possible (Berkeley 2006).

To achieve conservation objectives, many fisheries management bodies throughout the world have found it necessary to implement measures that could be argued to be comparable to MPAs. For example, a system of closed areas has been implemented to assist in meeting the conservation objective of rebuilding the depleted groundfish species managed by the Pacific Fishery Management Council (PFMC). In this system, the closed areas act to move the fishery out of regions where bycatch of depleted stocks would be highest. Ancillary benefits to habitat, diversity and other ecosystem services aside, the question of whether, and how, to incorporate protected areas as a strategic management tool to sustain low productivity stocks or otherwise optimize production of healthy stocks will be one that fisheries managers throughout the world are likely to consider to meet continually changing conservation objectives. However, policy decisions should be made with the awareness that adopting spatially based management could create new challenges for scientists and managers alike, particularly in regions with an infrastructure and history of using contemporary applied assessment models as the basis for decision making.

Within the USA, MPAs would not replace existing legislative obligations such as status determinations and the provision of estimates of optimal yields (OY) for target species. Consequently, two critical questions for managers to consider with respect to these obligations are: (1) whether/how the portion of the stock in the MPA is accounted for with respect to determination of stock status and depletion levels; and (2) whether restrictions on data collection inside the MPA would impact the ability to determine the 
status of the entire stock. The first question can be paraphrased as considering whether the spawning biomass within MPAs is 'on the table' or 'off the table' with respect to status determinations. In other words, would the biomass estimated to exist within the MPA be included as part of the total biomass when evaluating stock status and harvest policies. Given existing mandates to rebuild depleted stocks, the current answer is clearly that such biomass is 'on the table.' However, if MPAs were developed for a wider range of healthy stocks, the 'on the table' policy could lead to unfavourable management outcomes for healthy stocks and habitats that occur outside of the reserve (in the absence of a proportional reduction in effort), as the stocks outside the reserve would be subject to a proportionately greater fishing mortality rate than the status quo (Hilborn et al. 2006). This highlights that the 'on the table' approach might not result in an optimal environmental or socioeconomic outcome.

With respect to the second question, whether or not MPAs would restrict data collection within closed areas, it is clear that the inability to maintain time series of abundance estimates based on monitoring within closed areas could severely compromise the ability to assess the status of stocks. Although monitoring is an essential component of spatial management, the issue of how to monitor could be controversial. Moreover, greater patchiness in the distribution and abundance of resources could lead to greater variance in the data, and possibly greater uncertainty with respect to stockwide abundance and trends. This paper evaluates the likely and plausible impacts of MPAs on the scientific process that supports management, with examples drawn from the West Coast and elsewhere to provide context.

\section{MPAs, stock assessments and spatial modelling in marine ecosystems}

In a comprehensive review of fisheries and marine ecosystem simulation models that include spatial dynamics, Pelletier and Mahevas (2005) rated the potential for each modelling approach to address a range of effects described as important elements of the success (or lack thereof) of MPA implementation. These included restoring spawning biomass within MPAs, restoring demographic structure within MPAs, increasing fecundity, providing spillover, enhancing fisheries yield, improving population stability and resilience, protecting biodiversity and effecting changes in community structure. Overall, the review suggests that MPAs tended to meet the conservation goals of maintaining or restoring populations and population demographics. Although most studies suggest that yields would be likely to decline, even this broad generalization may be uncertain, as outcomes tend to be dependent on a range of assumptions related to larval dispersal, compensatory processes (including the life-history stage at which compensation takes place), maternal effects, movement and spillover (Botsford et al. 2003; Hilborn et al. 2004; Starr et al. 2004; Hart 2006; Berkeley 2006).

For example, Hart (2006) developed an analytical approach for assessing the effects of long-term closures on yield based on no movement between open and closed areas, and found that with MPAs, yields increased only when fishing mortality was greater than that associated with maximum sustainable yield (MSY). Similarly, using a spatially explicit multispecies simulation model of the Georges Bank region, Holland (2003) found that while area closures of $10-30 \%$ of fishable habitat resulted in modest increases in maximum potential revenue, they also increased the effort required to attain such revenue. The transient effects between existing and future conditions are also important considerations. For example, Hobday et al. (2005) evaluated the impact of MPAs established for habitat and biodiversity conservation on the recovery of rock lobster in the coastal waters of Victoria, Australia, and found that while MPAs would likely enhance the rate of recovery, they would also be likely to delay the recovery of the exploitable biomass in the areas open to fishing, because of the loss of fishable area.

From a more practical perspective, MPAs may pose a particularly complex challenge with respect to actually conducting the stock assessments from which status and yield are estimated. One necessary assumption of most assessment models is that the population being assessed has a high diffusivity, or alternatively, that all members of the target species are subject to the same fishing mortality rate as a result of the mobility and behaviour of the fishing fleet. This means that the effect of local recruitment events and regional fisheries are assumed to spread rapidly throughout the entire stock, which allows fishing mortality to be defined relative to the entire stock. The design of an MPA is based on the opposite assumption, which is that stocks are sufficiently viscous (low movement or diffusivity), that the protection afforded to the portion of the stock in the 
MPA will not quickly dissipate outside. In reality, there is clearly a continuum of diffusivity and viscosity in nature that is both stock dependent and difficult to quantify.

As the application of spatial management measures increases, it would be beneficial for most singlespecies assessment models to become spatially explicit. This is particularly important for high-viscosity stocks, as MPAs by design would be expected to further establish and maintain heterogeneous patterns of abundance, age and size distribution (Guénette et al. 1998; Holland 2002; Punt and Methot 2004, Hart 2006). Consequently, if largescale MPAs are implemented, stock assessment methods will likely need to account for spatial differences in population structure and movement patterns, both of which are poorly understood for most populations. Such considerations could potentially be incorporated into future assessments of datarich species, by using spatially stratified population models. However, few regions in the world are likely to have sufficient data on a majority of their stocks to support such data-intensive modelling efforts. For example, while a number of West Coast groundfish stock assessments are reasonably well supported by data, over half of the assessments conducted in the most recent assessment cycle can be described as data-moderate or data-poor (Table 1) and these are only a subset of the stocks that are included in the Groundfish Fishery Management Plan. As spatial management measures become both more complex and more important to sustainable resource management, accommodations that facilitate resource monitoring and assessment should be identified and implemented to support such transitions.

\section{The role of fisheries science in management}

The premise of contemporary fisheries science is that exploited populations are capable of compensatory

Table 1 Data availability (commercial, recreational and fishery-independent time series and demographic data) for most recent (2005 and 2006) stock assessments for West Coast groundfish.

\begin{tabular}{|c|c|c|c|c|c|c|c|c|c|c|c|}
\hline \multirow[b]{2}{*}{ Species or stock } & \multirow{2}{*}{$\begin{array}{l}\text { General } \\
\text { data quality }{ }^{1}\end{array}$} & \multicolumn{3}{|c|}{ Commercial data } & \multicolumn{3}{|c|}{ Recreational data } & \multicolumn{4}{|c|}{ Fishery Independent data } \\
\hline & & CPUE $^{2}$ & Age & Length & CPUE & Age & e Length & Trawl & Other ${ }^{3}$ & ${ }^{3}$ Age & Length \\
\hline Blackgill rockfish (Sebastes melanostomus) & Poor & & & $x$ & & & & $x$ & & & $x$ \\
\hline Bocaccio rockfish (S. paucispinis) & Good & & & $x$ & 2003 & & $x$ & $x$ & $x$ & & $x$ \\
\hline Cabezon (Scorpaenichthys marmoratus) & Moderate & & & $x$ & 2003 & & $x$ & & $x$ & & \\
\hline California scorpionfish (Scorpaena guttata) & Moderate & & & $x$ & 2003 & & $x$ & $x$ & $x$ & & \\
\hline Canary rockfish (S. pinniger) & Good & 1996 & $x$ & $\mathrm{x}$ & 1998 & $x$ & $\mathrm{x}$ & $x$ & & $x$ & $\mathrm{x}$ \\
\hline Cowcod (S. levis) & Poor & & & & 2000 & & $x$ & & $x$ & & \\
\hline Darkblotched rockfish (S. crameri) & Moderate & & $x$ & $x$ & & & & $x$ & & $x$ & $x$ \\
\hline Dover sole (Microstomus pacificus) & Good & 1995 & $x$ & $x$ & & & & $x$ & & $x$ & $x$ \\
\hline English sole (Pleuronectes vetulus) & Good & & $x$ & $x$ & & & & $x$ & & $x$ & $x$ \\
\hline Gopher rockfish (S. carnatus) & Poor & & & $x$ & 2004 & & $x$ & & & & \\
\hline Lingcod (Ophiodon elongatus) & Good & 1997 & $x$ & $x$ & & $x$ & $x$ & $x$ & & $x$ & $x$ \\
\hline Longspine thornyhead (Sebastolobus altivelis) & Moderate-poor & & & $\mathrm{x}$ & & & & $x$ & & & $x$ \\
\hline Kelp greenling (Hexagrammus decagrammus) & Poor & & & $x$ & 2002 & & $x$ & & & & \\
\hline Pacific hake (Merluccius productus) & Good & & $x$ & $x$ & & & & $x$ & $x$ & $x$ & $x$ \\
\hline Pacific Ocean perch (S. alutus) & Good & 1974 & $x$ & $\mathrm{x}$ & & & & $x$ & & $x$ & $\mathrm{x}$ \\
\hline Petrale sole (Eopsetta jordanı) & Moderate & 1999 & $\mathrm{x}$ & $x$ & & & & $x$ & & & $x$ \\
\hline Sablefish (Anoplopoma fimbria) & Good & 1988 & $x$ & $x$ & & & & $x$ & $x$ & $x$ & $x$ \\
\hline Shortspine thornyhead (Sebastolobus alascanus) & Moderate-poor & & & $x$ & & & & $x$ & & & $x$ \\
\hline Starry flounder (Platichthys stellatus) & Poor & 2004 & & & & & $x$ & & $x$ & & \\
\hline Widow rockfish (S. entomelas) & Moderate & 1999 & $x$ & $x$ & & & & $x$ & $x$ & & \\
\hline Yelloweye rockfish (S. ruberrimus) & Poor & & $x$ & $\mathrm{x}$ & 2000 & $x$ & $x$ & & & & \\
\hline Yellowtail rockfish (S. flavidus) & Good & 1999 & $\mathrm{x}$ & $x$ & & & & $x$ & & $X$ & $x$ \\
\hline
\end{tabular}

${ }^{1}$ This refers solely to the richness of data and the internal consistency of the data within the assessment, as qualitatively determined from the assessments and assessment reviews; this in no way reflects the abilities of assessment authors or teams.

${ }^{2}$ The year denotes the last year for which CPUE data were deemed adequate for use in assessing trends.

${ }^{3}$ These include larval abundance surveys (which index spawning biomass), pre-recruit surveys and submersible surveys. 
increases in per capita productivity in response to removals through fishing. Fishing increases the mortality rate of a given stock, leading to a smaller population of younger, faster growing individuals. Populations fished down below their equilibrium levels tend to have higher per capita production of young, which implies a density-dependent capacity to support some sustainable level of fishery removals. The ultimate objective in stock assessment science is to estimate both the abundance and the productivity of a given stock, in order to optimize the potential yield resulting from such compensation. Doing so requires estimating what the current biomass is, what the historical biomass has been, how productive the stock is, how much uncertainty there is around all of these measurements, and what the likely consequences of possible management actions (typically harvest levels) are.

A key role of fisheries management is to translate the guidance provided by fisheries scientists based on stock assessments into allowable harvest rates, catches and other management measures with the goal of maintaining populations at or above their target levels. Both the Magnuson-Stevens Fishery Conservation and Management Act (MSFCMA) in the USA and the UN FAO Code of Conduct for Responsible Fisheries, call for stock-specific biological reference points to serve as limits, targets and performance indicators for management actions when setting allowable fishing levels. For the USA fisheries, limit reference points are defined with respect to both fishing mortality (harvest) rates and biomass thresholds. Biomass thresholds, referred to in the USA as minimum stock size thresholds (MSST), are reference points that specify the relative biomass level at which a stock is considered overfished or depleted. The harvest rate associated with the MSY is also a limit reference point, and is referred to as the maximum fishing mortality threshold (MFMT, or alternatively, $\mathrm{F}_{\mathrm{MSY}}$ ). Exceeding this harvest rate (or the associated catch, referred to as the allowable biological catch or $\mathrm{ABC}$ ) is considered overfishing according to current USA law. Target catches, known as OY, are legally defined in the USA as the ABC values as reduced by relevant ecological or socioeconomic factors. The objective for most stock assessments is to develop and integrate life-history, catch and relative abundance information into a statistical model to estimate absolute stock abundance, reproduction and mortality relative to these established management limits and targets.
The very earliest reference points were based on estimating the MSY of a given population using the logistic growth curve (Schaefer 1954). These simple curves predicted that populations were most productive when fished down to half of their unfished biomass. As population models became more complex, it was found that the population size at which MSY is predicted to occur, $\mathrm{B}_{\mathrm{MSY}}$, was actually very difficult to estimate and sensitive to model assumptions. As a result, both $\mathrm{F}_{\mathrm{MSY}}$ and $\mathrm{B}_{\mathrm{MSY}}$ are now commonly based on 'proxies' that can be determined from readily available fisheries data and models. For example, the fishing mortality rate that reduces spawning biomass per recruit (SPR) to levels ranging from $35 \%$ to $50 \%$ of the unfished level $\left(\mathrm{F}_{35 \%}, \mathrm{~F}_{50 \%}\right)$ have been used as both targets and limits for many fisheries (Clark 1991, 1993; Goodman et al. 2002; Ralston 2002).

Stock assessment models generally require three categories of information: total catch (what has been removed), life-history information (growth, maturity and natural mortality), and absolute or relative abundance data to determine trends in abundance. $^{2}$ Age- and length-structured models require more detailed demographic data (catch age- and length-composition information), but are better able to adjust for the details of fishery selectivity, use multiple data sources and make realistic projections. In a typical stock assessment, observed catch demographic and trend data are fitted to predicted values by varying model parameters related to, for example, recruitment, mortality, selectivity and productivity (primarily the steepness of the spawner/recruit function). The principal types of information used in stock assessment models are shown graphically in Fig. 1, and the extent to which MPAs could potentially affect each of these types of information is examined in the following sections.

\section{Fishery-dependent information}

Fishery-dependent information includes retained catch, discarded catch, demographic characteristics of the catch (generally its age, sex and size compositions) and catch per unit of nominal effort (CPUE).

\footnotetext{
${ }^{2}$ The assessment model Stock Synthesis 2 (SS2; Methot 2000, 2005) is used most widely for modelling stock abundance and productivity for fisheries off the West Coast of the USA, primarily because it was designed to use the mix of length, age, trend and discard data commonly available for these stocks.
} 
Figure 1 Principal sources of data and information used in most ageand length-structured stock assessments.

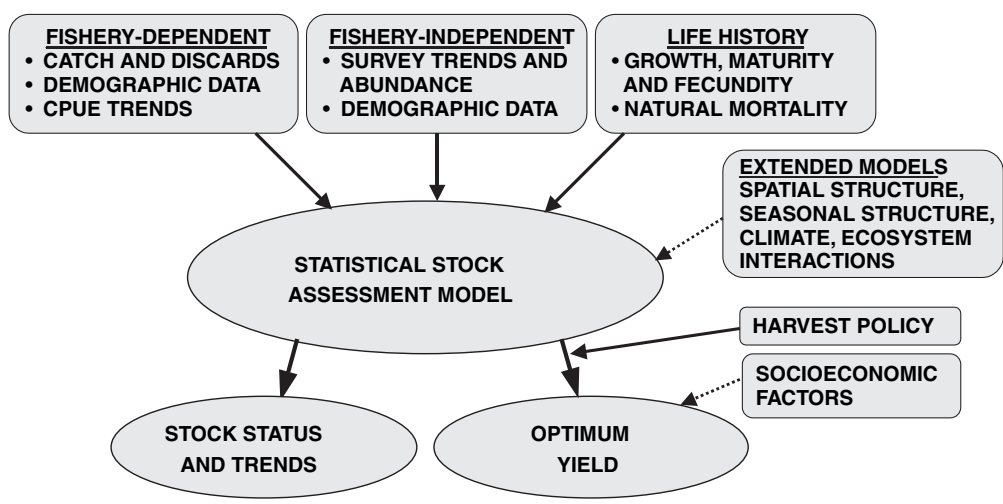

may be stable in the face of stock declines as a result of increasing fishing power or changing spatial patterns in effort (Hilborn and Walters 1992; Walters 2003). Furthermore, management measures can substantially alter the integrity of fisherydependent data, particularly for resources that are considered overfished or depleted and consequently become subject to efforts by managers to reduce or control catches. For example, in response to declines in rockfish abundance, trip limits off the USA West Coast have become increasingly restricted over time (e.g. Fig. 2), culminating in complete non-retention of some species and massive closures of habitat in recent years. As a result, for all but one of the nine assessments in Table 1 that included commercial CPUE indices, the index was truncated by 2000 because of difficulties interpreting catch rates given the impact (perceived or otherwise) of regulatory changes. CPUE indices based on data from recreational fishers have largely continued to be used for several West Coast groundfish assessments where

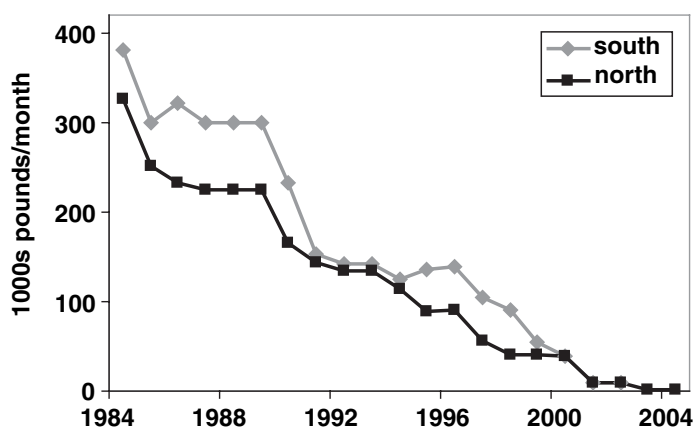

Figure 2 Example of regulatory changes that may bias catch per unit effort (CPUE) time series as indices that change linearly with changes in abundance, shown are changes in bimonthly trip limit equivalents for West Coast rockfish (all Sebastes species except splitnose rockfish, $S$. diploproa) south and north of Cape Mendocino, CA. 
fishery-independent surveys are lacking or particularly imprecise. Standardization of these CPUE data typically involves analysis of the spatial (depth) and temporal (seasonal) restrictions that primarily affected catch rates in these fisheries (Maunder and Punt 2004; Stephens and MacCall 2004) so there is some confidence that the standardized annual index represents the trend in stock abundance.

\section{Life-history information}

For heavily exploited or depleted species, estimates of life-history parameters are often not available or reliable as a result of substantial compression of age and size distributions. For example, Kronlund and Yamanaka (2001) found differences in growth parameters in lightly versus heavily exploited aggregations of yelloweye rockfish (Sebastes ruberrimus) off British Columbia, which they attributed in part to a lack of older fish in the heavily exploited site. Bobko and Berkeley (2004) evaluated the consequences of maternal age on black rockfish (S. melanops) larval survival and timing of postparturation, yet had difficulties in finding adequate numbers of older females with which to conduct their analysis (S. Berkeley, personal communication). Consequently, it is possible that MPAs may provide a source of specimens and data for larger, older individuals for biological studies. For example, Attwood (2003) estimated natural mortality rates for the galjoen (Dichistius capensis) from large MPAs off South Africa, and Punt et al. (2001) used a simulation model to show that there was some improvement in estimates of natural mortality rates for coral trout (Plectropomus leopardus) when data from MPAs were available. However, Punt and Methot (2004), also using a simulation model, found that MPAs improved the ability to estimate natural mortality and other biological parameters only modestly.

Marine protected areas also have the potential to alter life-history parameters such as growth and natural mortality rates as a result of changes in community structure (predator, competitor and prey abundance). For example, Salomon et al. (2002) modelled the effects of MPA zoning policies in British Columbia using Ecospace (Walters et al. 1999) and predicted that top predators were likely to cause localized depletion of some prey species, possibly resulting in trophic cascades. ${ }^{3}$ Similarly, Martell et al. (2005) modelled the effects of implementing large-scale MPAs in the North Pacific to protect pelagic loggerhead and leatherback sea turtles, as well as marlin populations, all of which are facing substantial conservation problems. They found that although closed areas had the potential to reduce turtle bycatch mortality, this could also lead to greater predation mortality for both turtles and marlin. ${ }^{4}$ In contrast, for groundfish communities in the California Current, empirical evidence suggests that higher trophic level rockfish play a structuring role in the ecosystem, such that habitats with high piscivore density are associated with few of the small, fast-growing and early-maturing rockfish species found in high abundance in heavily fished environments (Stein et al. 1992; Yoklavich et al. 2000; Levin et al. 2006). Moreover, theoretical considerations suggest that smaller species of rockfish could consume or outcompete recruiting juveniles of larger species under scenarios of heavy exploitation for the higher trophic level species, potentially leading to shifts in equilibrium conditions (MacCall 2002; Baskett et al. 2006). Baskett et al. (2006) found that under such conditions, area closures could be among the most effective means of ensuring that a given species or guild is able to persist and maintain their functional role in a habitat or ecosystem.

Such observations lead to two basic conclusions. The first is that fisheries themselves, through ecosystem changes, trophic interactions and cascades, and selective forces on demographic characteristics, have the potential to alter life-history characteristics such as growth, natural mortality and maturity rates, which would not be expected to be time invariant even in an unfished system (Hollowed et al. 2000; Pauly et al. 2002; Walters et al. 2005). The second is that regardless of

\footnotetext{
${ }^{3}$ It has also been acknowledged that some conservation objectives are not achievable simply by implementing MPAs. For example, empirical studies of sea otter and abalone interactions suggest that some California nearshore MPAs may not be able to serve the dual purpose of biodiversity enhancement and abalone conservation, as the abundance of abalone in the presence of sea otters will be too low to contribute to regional fishery sustainability (Fanshawe et al. 2003).

${ }^{4}$ Both these authors and others have qualified such general results by noting that this type of modelling approach is limited in its ability to capture demographic structure and ontogenetic migrations at the population level, and, as such, may be limited in their ability to predict impacts to community diversity.
} 
whether such changes have occurred, the implementation of MPAs could also result in shifts in life-history characteristics, presumably (but not reliably) in the opposite direction. Although the direction of such factors would be difficult to either assess or predict, the possibility that such characteristics may not be the same inside MPAs as outside is something of which those who develop or apply such information should be cognizant. However, even with the recognition that mean values for growth, mortality or other factors within MPAs might not reflect mean values outside of MPAs, the potential to gain insight regarding the range or plasticity of such values could be important. Perhaps more significantly, MPAs could play a role in preserving genotypic diversity and age structure in exploited populations. Fishing has been widely accepted (and experimentally demonstrated) to be a form of artificial selection towards both smaller size and earlier maturity (Mangel et al. 1993; Conover and Munch 2002). The potential consequences of such selection are important for both conservation and economic reasons. By protecting a fraction of a given stock from the evolutionary consequences of fishing, MPAs could provide a refuge for fish genetically predisposed to fast growth, late maturity or large size at age. Similarly, it has been argued that a broad age structure is beneficial to the recruitment and productivity of many stocks (Berkeley et al. 2004), and area closures offer one of very few means of achieving a broad age structure based on currently available management practices (Berkeley 2006).

\section{Catch demographic data}

A major source of information for most contemporary stock assessments, particularly those in temperate waters, is demographic data (catch at age and/ or catch at length) taken directly from fisheries catches. Such information is an important component of most (21 of 22) of the stock assessments in Table 1 and contributes to the estimation of fishing mortality as well as the relative strengths of the year-classes reflected in the catch. With low rates of mixing, it is reasonable to assume that the age structure of the population in an MPA would be similar to that in the unfished state whereas that in the fished area would reflect the impact of fishing. The mixing of animals across MPA boundaries can be problematic for an assessment at low mixing rates, as the age structure of the exploited area will not reflect the impact of fishing mortality. Depending upon movement rates and other factors, older and/or large fish can be expected to be overrepresented in catches near the boundary (Kramer and Chapman 1999; Sladek-Nowlis and Roberts 1999). This has been widely demonstrated in a number of studies of both fishes (Johnson et al. 1999; McClanahan and Mangi 2000; Russ et al. 2003; Willis et al. 2003) and invertebrates (Cox and Hunt 2005; Hobday et al. 2005; Goñi et al. 2006). Although such spillover represents productivity that can contribute to overall yield for a given resource, the consequences of diffusion of old fish outside reserve boundaries and into fisheries catches could cause assessment models to misinterpret the population size of the whole stock (Punt and Methot 2004). However, it is worth noting that such diffusion may already be a factor in contemporary assessments, when animals that inhabit untrawlable habitat (natural refugia) diffuse randomly or at high densities to trawlable areas. Furthermore, with high rates of mixing the effect is unlikely to be significant.

\section{Fishery-independent surveys}

Fishery-independent surveys are specifically designed to be a reliable source of information on trends in stock abundance (NRC 1998). On the West Coast, the results from such surveys were used in 15 of the 23 assessments in Table 1. Additionally, surveys are often a primary source of the biological data used to estimate life-history parameters. Most fishery-independent survey techniques involve lethal sampling (e.g. to obtain otoliths for age determination) and may impact the habitat. Although monitoring is typically considered to be an essential element of MPA-based approaches for resource management (NRC 2001; Gerber et al. 2005), the issue of how to monitor has the potential to be controversial if extractive methods have been used in traditional surveys. Although non-lethal means of estimating abundance (such as direct observation surveys from submersibles or towed vehicles) offer an alternative way to track abundance and size structure, particularly in areas difficult or impossible to sample with trawl or other extractive survey gear (Richards 1986; O'Connell and Carlile 1993; Jagielo et al. 2003), these surveys also have limitations. For example, the spatial extent covered is considerably less than in trawl surveys, there is an inability to collect age, maturity 
and often sex information, length information exist, but has a higher variance, and the cost may be prohibitive. Other non-lethal survey methods include egg or larval abundance (or production) surveys (Mangel and Smith 1990; Moser et al. 2000; MacCall 2003; Ralston et al. 2003) and hydroacoustic surveys (Stanley et al. 2000; Helser et al. 2006), none of which would presumably be affected by area closures. However, any new indices of abundance based on non-lethal methods cannot replace historical time series without a period of overlap and calibration.

Along the US West Coast, large closed areas were recently enacted to protect essential fish habitat (EFH) from trawling, encompassing many areas that have historically been surveyed using trawl gear (Fig. 3). Over 5\% of historical shelf survey tows, and nearly $10 \%$ of historical slope survey tows, have been conducted in these areas, although interestingly a higher rate of bad performance tows have been documented from these areas (Zimmermann
2003), consistent with the intent of protecting high relief habitat in implementing EFH. If surveys were excluded or constrained from MPAs, the ability to track abundance and demographics throughout the range of a species could be compromised, although establishing MPAs in areas with complex bottom topography, or other areas in which trawl survey methods have not been used, would have negligible impacts. However, even with no constraints on surveys, the imposition of a (large) MPA may have substantial implications for survey stratification and design. Specifically, changes in the abundance and demographic composition of stocks inside MPAs could lead to the need to either stratify survey effort, or post-stratify survey results, with explicit consideration of MPA boundaries. For example, along the US East Coast, most of the biomass of yellowtail flounder (Limanda ferruginea) has been found within the closed areas implemented to rebuild that (and other) groundfish stocks (Legault and Stone 2004). The failure to allocate and stratify survey effort
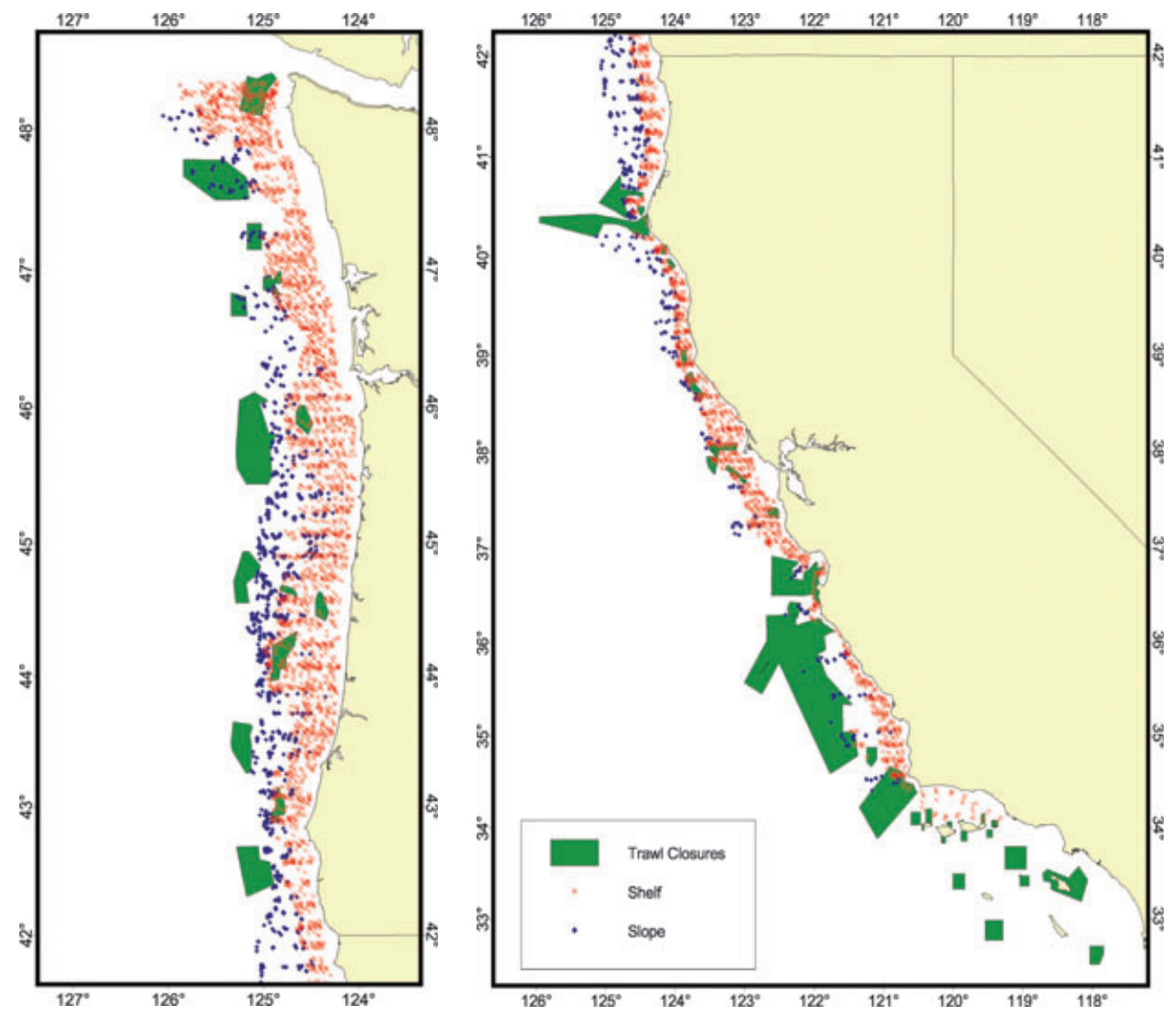

Figure 3 The closed areas recently implemented by the Pacific Fishery Management Council to protect essential fish habitat, and the locations of trawl survey tows from two surveys (red, 50-550 m; blue, 186-1200 m). 
consistently within and outside of these areas could result in increasing the variance in the abundance time series, as could the simple consequence of having greater spatial heterogeneity in the distribution of the resource itself.

\section{Spatial variability and movement patterns}

Movement and dispersal of larvae, juveniles and adults impact both the efficacy of MPAs and the likelihood of increased or decreased yields in fisheries. With respect to larval and juvenile movement, it is worth noting that population persistence is greater if there is not much dispersal, but increased (or maintained) yield is more likely if dispersal is fairly extensive (Botsford et al. 2004). Issues relating to larval and juvenile dispersal are not addressed in this paper, because these have been reviewed extensively elsewhere (Warner et al. 2000; Gaines et al. 2003; Botsford et al. 2004). Instead, we briefly review what is known about movement patterns for the adults of the major groundfish species and assemblages presented in Table 1, and consider what this might infer about the ability to conduct stock assessments and understand changes in fishing behaviour.

A reasonable amount of information is known about the seasonal, ontogenetic and nomadic movement rates for the key species and assemblages of groundfish along the USA West Coast (Table 2). There is clearly a wide range of movement patterns for groundfish in the California Current System. For example, large-scale $(>1000 \mathrm{~km})$, highly predictable seasonal movements of Pacific hake are observed coastwide, while many flatfish (as well as lingcod and California scorpionfish) have distinctive seasonal migrations across depth strata. In addition, many species are relatively mobile (nomadic) on both small (lingcod, California scorpionfish) and large (sablefish) spatial scales. By contrast, the limited evidence for most rockfish suggests that the bulk of the adults are highly sedentary, with some gradual ontogenetic movement to greater depths common for most shelf and slope species. As a result, MPAs would presumably protect 'islands' of individuals for rockfish, such that these species would presumably show greater contrast in age and size structures inside and outside of MPAs. The observation that the stocks most vulnerable to overfishing in the California Current System also appear to be the most viscous with respect to movement rates might suggest that the spillover of such species would be low, while the spillover of more productive species such as sablefish, lingcod and flatfish (with generally higher movement rates) could be greater. If so, this would also suggest that monitoring and assessment efforts will have a greater need to consider such heterogeneity in assessing stock status and trends for rebuilding stocks. However, it is also feasible that future management strategies could utilize MPAs not only to hasten the rebuilding of depleted stocks, but to ensure their persistence while allowing for fishing opportunities on co-occurring healthy stocks in open areas. This is particularly true for some of the higher trophic level, and more vulnerable, species such as yelloweye rockfish and cowcod ( $S$. ruberri$m u s$ and $S$. levis respectively), for which sustainable yields even over the long term are expected to be a small fraction of historical catches.

\section{Structure of assessment models}

Punt and Methot (2004) conducted a quantitative evaluation of the effects of implementing large-scale MPAs on the performance of stock assessment methods. Using the Management Strategy Evaluation approach, ${ }^{5}$ they found that while the negative impacts of MPAs on assessments were substantial if MPA and non-MPA data were aggregated, the impacts were minor when spatially structured models were used. Bias and errors increased with movement rate, particularly when movement increased with age, because the models treated each area separately; performance was less sensitive to assumptions about larval dispersal and density dependence. Not surprisingly, a lack of fisheryindependent survey data for the population inside the MPA led to considerably degraded model performance. Overall, the study suggested that the negative impacts of MPAs on assessment ability were relatively slight if measures were taken to account for spatial patterns in demography and abundance (e.g. if MPA and non-MPA data are kept separate), although the simulations were based

\footnotetext{
${ }^{5}$ Management strategy evaluation involves developing an (operating) model that reflects reality and using this model to generate data on which assessments could be based. The ability of stock assessment models to estimates quantities of management interest can be determined by comparing the estimates from the assessment model (which uses the generated data) with the true values from the operating model.
} 


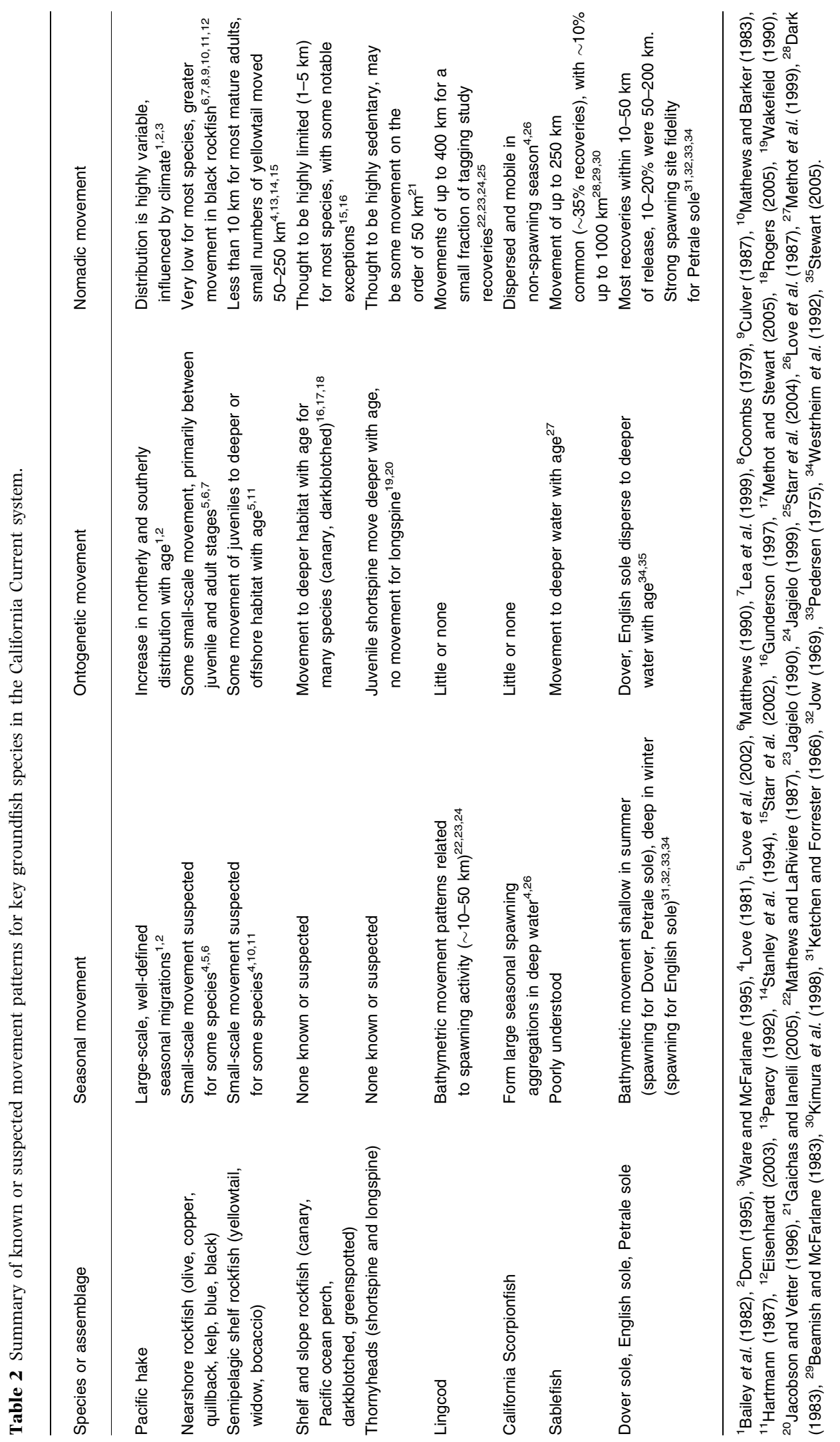


upon relatively data-rich species with low rates of adult movement. Moreover, these results were based on there being a relatively large, contiguous MPA, rather than a large number of more moderately sized MPAs, and it is not clear whether the results obtained by Punt and Methot (2004) are robust to alternative MPA designs.

Ideally, stock assessment models for species subject to MPAs or other area closures should explicitly account for variability in population demographics. For example, depending upon mixing rates and demographic variability, one might include three spatial units (protected, exploited and MPA-adjacent edge areas) in an assessment for a species that is found to some extent in an MPA. However, moving to even a three-area model would require both a substantial shift in the basic modelling framework and a tremendous increase in the amount and quality of demographic data from open and closed areas. Quantifying and understanding movement and migration rates would become a critical new focus for assessment-related research. If data or modelling were not sufficient to explicitly account for spatial differences in the age or size structure of the population, the trends and population structure inferred by catch-at-age and catch-at-length data may not accurately reflect the demographic status of the population.

In cases in which the data are too sparse to apply a fully spatial model, a reasonable compromise to ignoring spatial structure might be to allow the availability of fish of different ages/sizes to drop off with age. Allowing for declining availability with age/size is already common when conducting stock assessments for species such as shortspine thornyheads (S. alascanus), for which there is an apparent ontogenetic movement of older (larger) individuals of both sexes into deeper water. The assumption of declining availability with age/size (Fig. 4) implies that a reservoir of larger, older individuals exists in a population that is less vulnerable to fishing gear than their smaller, younger counterparts, which might superficially mimic the impact of an MPA. However, dome-shaped selectivity has the potential to be misleading in some circumstances, and consequently this approach is not likely to be a reasonable means of approximating differences in vulnerability across space, in general. Specifically, it implicitly implies that the trend in abundance inside and outside the MPA is the same, and could result in a change in the apparent selectivity over time, neither of which is likely to reflect reality.

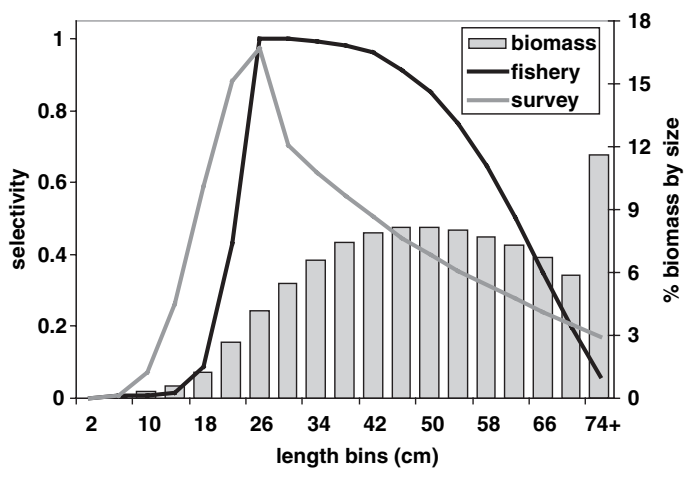

Figure 4 Population length structure and length-based selectivity curves for shortspine thornyheads (Sebastolobus alascanus) (Hamel 2005).

As Schnute and Richards (2001) point out, the principal assumptions behind assessment models are often challenged by a mix of complex biological, oceanographic and interspecific interactions, as well as by ever changing fisheries practices and management measures. Most, if not all, of these assumptions are not fully met in reality. Wilen (2004) notes that applied fisheries science has lagged behind more academic research in marine ecology with respect to adopting an increasingly 'spatially rich' interpretation of the complexity in population, subpopulation and metapopulation structure in marine populations. This is largely because of the extensive data necessary to adopt such a spatially explicit body of research. Although it is true that few stock assessments have confronted spatial variability in abundance, demographics and dispersal, there are a modest, but increasing, number of examples in which such factors have been incorporated into catch-atage (or catch-at-length) models, such as northern Atlantic cod (Fu and Fanning 2004), school shark off southern Australia (Punt et al. 2000) and southern Pacific tunas (Fournier et al. 1998; Hampton and Fournier 2001). In all of these examples, the increase in model complexity was substantial. For example, Punt et al. (2000) found that while adding spatial complexity and movement was warranted by evidence and stakeholder concerns, movement parameters ultimately accounted for 36 of the 50 parameters used in the model and made quantifying the uncertainty in the model results more difficult. Similarly, while Hampton and Fournier (2001) found that including spatial structure in an assessment of yellowfin tuna allowed the model to better replicate the patchiness in population distribution and exploitation (critical for facilitating multina- 
tional management of the resource), the high complexity of the model limited their ability to test many alternatives to the base model design. Advances in both assessment and simulation methods should provide the means to incorporate such complexity into fisheries science and management approaches in the future.

\section{Fisheries management objectives and obligations}

Most Fishery Management Councils in the USA have implemented large-scale closed areas to rebuild depleted species and to protect $\mathrm{EFH}(\mathrm{Mu}-$ rawski et al. 2000; Holland 2005). The duration of such closures is reflective of the particular issue they are intended to address. For instance, the PFMCs gear restrictions and closures implemented to protect EFH are likely to be quasi-permanent, while the rockfish conservation areas (RCAs) were designed to reduce the incidental bycatch of rebuilding rockfish species, and were not intended to be permanent management features. Factors associated with the implementation of large-scale closed areas are best understood in the context of the fishery management process in the USA, depicted here in the form of a simplified schematic of the PFMC process (Fig. 5). The management cycle is initiated with the stock assessments, the structure of which was described in detail earlier. Following scientific review, assessment results are transmitted to management and advisory bodies, where they form the basis for decisions regarding ABCs, OYs and, for overfished species, rebuilding targets. For example, most West Coast groundfish fisheries are multispecies in nature (as are comparable fisheries in the North Pacific, Northeast Atlantic and elsewhere); consequently, speciesspecific OYs take account of the assemblages within which each species is caught.

Fishery Management Councils, and the agencies that review and approve their regulations, are responsible for ensuring that the regulatory process yields a reasonable range of management alternatives (relative to each issue under consideration), and that each alternative is evaluated in terms of its

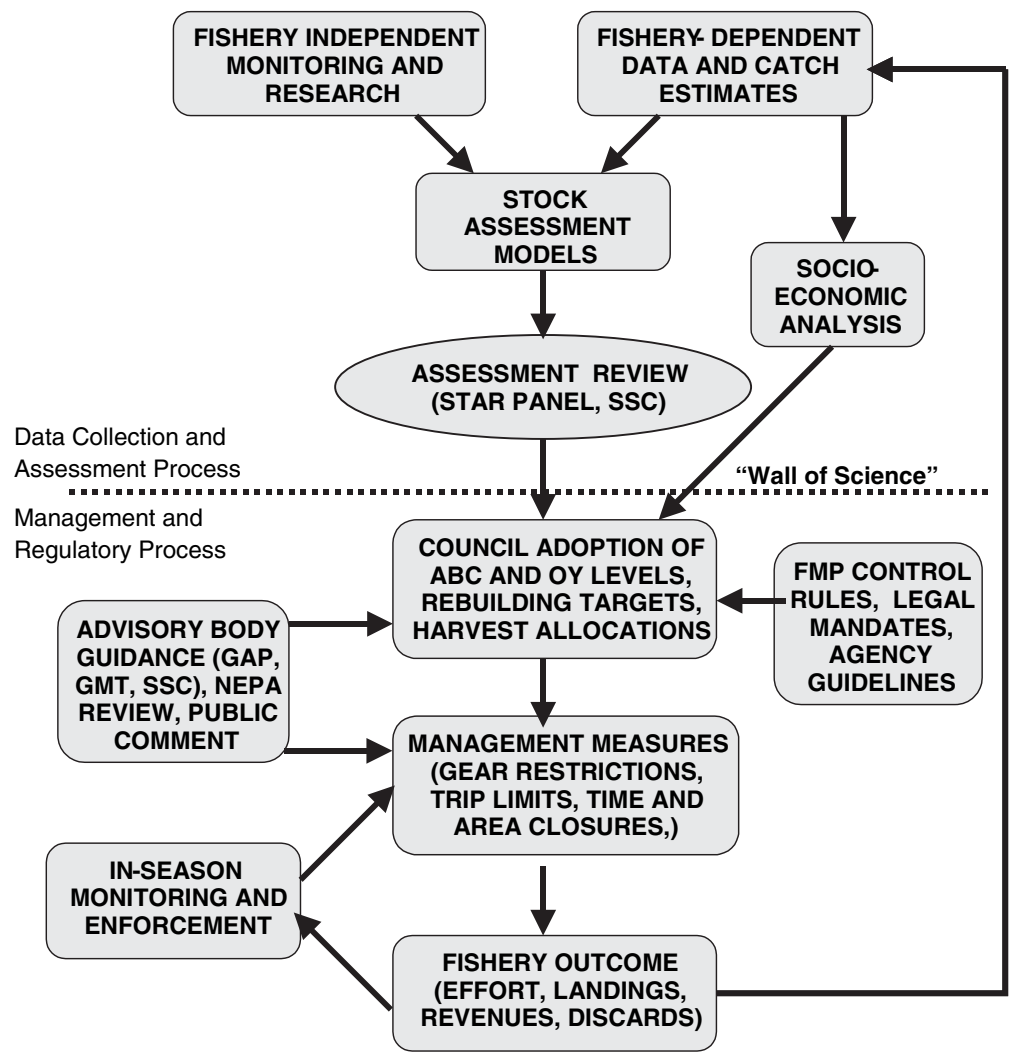

Figure 5 Schematic overview of the Pacific Fishery Management Council process for developing and using the scientific recommendations from resource assessments as the basis for management measures and fishery outcomes. 
biological, environmental and socioeconomic effects, monitoring and enforcement requirements and allocation implications. These requirements help ensure that the Council and the public are aware of the consequences of management alternatives prior to the selection of a preferred alternative. Stock assessments and regulatory analyses are subject to a wide range of dynamic environmental and economic influences, as well as intrinsic observation and model uncertainty. Such uncertainty is explicitly reflected in stock assessments and regulatory analyses and in the adoption of precautionary management measures (such as setting OYs at levels below ABCs). Uncertainty in pre-season effort and catch projections is addressed by intensive in-season monitoring and in-season regulatory changes (including the possibility of early fishery closure) as warranted.

In common with most management systems, the regulatory infrastructure that supports the PFMC process has had to adapt to the increasing demands of spatial management. Spatial data were essential for establishing the boundaries of the RCAs and continue to be used for monitoring changes in effort and catch in the open area. The need for an observer programme became more compelling to monitor both the magnitude and the spatial distribution of discards, and such a program was established in 2001. While spatial closures are not unique in terms of precipitating displacement of effort to other fisheries, the RCAs led to the development of customized spatial bycatch models that predict the effect of RCA boundary changes on displaced effort and consequent changes in the catch of target and bycatch species. ${ }^{6}$ Although this should not imply that all important data and methodological issues associated with their use have necessarily been resolved, the long time periods expected for several of the rebuilding stocks suggest that spatial management measures will remain an important element of the management toolbox into the foreseeable future. The experience of the PFMC and other management bodies with spatial management points out the need for data and models that suit real world, operational needs of

\footnotetext{
${ }^{6} \mathrm{~A}$ description of this model and the way in which it is applied in West Coast groundfish management can be found in Chapter 4 of the 2005-2006 Groundfish FMP Management Specifications Environmental Impact Statement (EIS), available online at http://www.pcouncil.org/ groundfish/gfspex/gfspex05-06.html.
}

managers, as well as the need for managers to scale their priorities and expectations to the limits of scientific capability and institutional capacity.

\section{Summary}

There is general agreement that MPAs can result in benefits for marine ecosystems, particularly in situations where scientific information is scarce, management measures and enforcement are weak, and resources are depleted below target levels (NRC 2001; Halpern 2003; Alcala et al. 2005). Clearly, spatial management measures also have a role to play in facilitating the recovery of rebuilding species, as evidenced by the increasing implementation of large-scale closed areas in temperate water fisheries worldwide. However, there is an ironic twist to the role that MPAs may play in rebuilding populations that have been historically depleted, as the ability to assess stock status and trends may be compromised to some extent as a result of their implementation. The issue of bias is important with respect to the impact on the ability to conduct assessments, as there is the potential to bias assessment results in either direction. For example, if catch-at-age models are based on demographic data from open fished areas only, the result could be a more 'risk adverse' bias to overestimate fishing mortality throughout the entire range of the stock. However, if an assessment is structured to estimate fishing mortality only on the fraction of the stock outside MPAs, yet there are larger, older fish from within MPA moving across boundaries and being caught in fisheries, the bias could be in the other direction. In general, the direction of bias is not likely to be predictable, and will depend both on the life history of the stock, the dynamics of the fishery and the nature of the management regime. For instance, the question of whether the biomass within MPAs is on or off the table with respect to estimating stock status relative to target mortality rates and reference points will have a much greater influence on the extent to which a management approach might be risk prone or risk adverse.

The impacts described here are based on the technical consequences to status quo science and management systems, which are themselves evolving and changing over time. For managers, the policy considerations related to choices of whether and why to implement MPAs are (and should be) larger than the considerations described in the paper. Spatially based management has proven to 
be critical to meeting conflicting management goals and objectives, such as maintaining fishing opportunities on healthy stocks while reducing incidental catches of rebuilding species, and meeting habitat protection requirements. Furthermore, there is a growing appreciation of the significance of heterogeneity in population structure for most marine organisms, as well as for the potential interaction between population structure and fishing behaviour, that scientists and managers alike will find increasingly necessary to confront in population models and management measures (Berkeley et al. 2004; Wilen 2004; Pelletier and Mahevas 2005). For example, a recent NRC Committee on the Ecosystem Effects of Fishing found that 'Spatial analyses may be one of the greatest obstacles faced by fishery managers, yet new developments in measurement and analysis methods allow for the explicit consideration of spatial variability in marine systems' (NRC 2006). This committee recommended a new focus on the collection and analysis of spatially explicit data to monitor and assess populations at both large and fine scales. While nearly everyone can agree on a perceived need to move in this direction, policy decisions should be made with awareness of the real or potential consequences, and with the recognition that new policy objectives and implementation measures create new suites of challenges, each of which may have their own cadre of supporters, methods, assumptions and objectives. Just as predicting the impacts of MPAs on total fisheries yield with any meaningful confidence tends to be based on a range of immeasurable caveats and assumptions, the actual impacts of implementing MPAs on the systems established to monitor and manage resources is to some extent unpredictable.

\section{Acknowledgements}

This manuscript is a product of the NOAA Working Group to integrate the science of MPAs and Fishery Science and Management, and we thank all of the participants of the Working Group for their guidance and feedback. We thank Steve Berkeley, Devora Hart, Alec MacCall, Steve Ralston, Daniel Waldeck, Lisa Wooninck and Anna Zagorska for their thoughtful comments and review of earlier drafts of this manuscript, and we are grateful to the Editor and two anonymous reviewers for their helpful comments, suggestions and observations. We also thank E.J. Dick for help with Fig. 3, Owen
Hamel for providing the data for Fig. 4, and Chris Legault for comments on the yellowtail flounder stock assessment.

\section{References}

Alcala, A.C., Russ, G.R., Maypa, A.P. and Calumpong, H.P. (2005) A long-term, spatially replicated experimental test of the effect of marine reserves on local fish yields. Canadian Journal of Fisheries and Aquatic Sciences 62, 98108.

Attwood, C.G. (2003) Dynamics of the fishery for Galjoen Dichistius capensis, with an assessment of monitoring methods. African Journal of Marine Science 25, 311-330.

Bailey, K.M., Francis, R.C. and Stevens, P.R. (1982) The life history and fishery of Pacific whiting, Merluccius productus. CaPCOFI Reports 23, 81-98.

Baskett, M.L., Yoklavich, M. and Love, M.S. (2006) Predation, competition, and the recovery of overexploited fish stocks in marine reserves. Canadian Journal of Fisheries and Aquatic Sciences 63, 1214-1229.

Beamish, R.J. and McFarlane, G.A. (1983) Summary of results of the Canadian sablefish tagging program. In: Proceedings of the International Sablefish Symposium (Lowell-Wakefield Fisheries Symposia Series, Anchorage, 2931 March 1983). B.R. Melteff, ed. University of Alaska Sea Grant Report 83-8, Fairbanks, AK, pp. 147-184.

Berkeley, S.A. (2006) Pacific rockfish management: are we circling the wagons around the wrong paradigm? Bulletin of Marine Science 78, 655-668.

Berkeley, S.A., Hixon, M.A., Larson, R.J. and Love, M.S. (2004) Fisheries sustainability via protection of age structure and spatial distribution of fish populations. Fisheries 29, 23-32.

Bobko, S.J. and Berkeley, S.A. (2004) Maturity, ovarian cycle, fecundity, and age-specific parturition of black rockfish, Sebastes melanops. Fishery Bulletin 102, 418429.

Botsford, L.W., Micheli, F. and Hastings, A. (2003) Principles for the design of marine reserves. Ecological Applications 13, S25-S31.

Botsford, L.W., Kaplan, D.M. and Hastings, A. (2004) Sustainability and yield in marine reserve policy. In: Aquatic Protected Areas as Fisheries Management Tools (American Fisheries Society Symposium 42, Quebec, Canada, 11-12 August 2003). J.B. Shipley, ed. American Fisheries Society, Bethesda, MD, pp. 75-86.

Clark, W.G. (1991) Groundfish exploitation rates based on life history parameters. Canadian Journal of Fisheries and Aquatic Sciences 48, 734-750.

Clark, W.G. (1993) The effect of recruitment variability on the choice of target level of spawning biomass per recruit. In: Proceedings of the International Symposium on Management Strategies for Exploited Fish Populations (Lowell-Wakefield Fisheries Symposia Series, Anchorage, AK, 21-24 October 1992). G. Kruse, D.M. Eggers, R.J. 
Marasco, C. Pautzke and T.J. Quinn, eds. University of Alaska Sea Grant AK-SG-93-02, Fairbanks, AK, pp. 233-246.

Conover, D.O. and Munch, S.B. (2002) Sustaining fisheries yields over evolutionary time scales. Science 297, 94-96.

Coombs, C.I. (1979) Reef Fishes near Depoe Bay, Oregon: Movement and the Recreational Fishery. MS Thesis. Oregon State University, Corvallis, OR, 39 pp.

Cox, C. and Hunt, J.H. (2005) Change in size and abundance of Caribbean spiny lobsters Panulirus argus in a marine reserve in the Florida Keys National Marine Sanctuary, USA. Marine Ecology Progress Series 294, 227-239.

Culver, B. (1987) Results from tagging black rockfish (Sebastes melanops) off the Washington and northern Oregon coast. In: Proceedings of the International Rockfish Symposium (Lowell-Wakefield Fisheries Symposia Series, Anchorage, AK, 20-22 October 1986). B.R. Melteff, ed. University of Alaska Sea Grant Report 87-2, Fairbanks, AK, pp. 231-240.

Dark, T.A. (1983) Movement of tagged sablefish released at abundance index sites off Southeastern Alaska, Washington, Oregon and California during 1978-81. In: Proceedings of the International Sablefish Symposium (Lowell-Wakefield Fisheries Symposia Series, Anchorage, March 29-31, 1983). B.R. Melteff, ed. University of Alaska Sea Grant Report 83-8, Fairbanks, AK, pp. 191-208.

Dorn, M.W. (1995) The effects of age composition and oceanographic conditions on the annual migration of Pacific whiting, Merluccius productus. CalCOFI Reports 36, 97-105.

Eisenhardt, E.P. (2003) Acoustic Telemetry of Rocky Reef Fish Home Range to Evaluate Marine Protected Area Size. San Juan County Marine Resources Committee Report, Friday Harbor, WA, 18 pp.

Fanshawe, S., Vanblaricom, G.R. and Shelly, A.A. (2003) Restored top carnivores as detriments to the performance of marine protected areas intended for fishery sustainability: a case study with red abalones and sea otters. Conservation Biology 17, 273-283.

Fournier, D.A., Hampton, J. and Sibert, J.R. (1998) MULTIFAN-CL: a length-based, age-structured model for fisheries stock assessment, with application to South Pacific albacore, Thunnus alalunga. Canadian Journal of Fisheries and Aquatic Sciences 55, 2105-2116.

Fu, C. and Fanning, L.P. (2004) Spatial considerations in the management of Atlantic Cod off Nova Scotia, Canada. North American Journal of Fisheries Management 24, 775-784.

Gaichas, S. and Ianelli, J. (2005) Gulf of Alaska thornyheads. In: North Pacific Groundfish Stock Assessment and Fishery Evaluation Reports for 2006. North Pacific Fishery Management Council, Anchorage, AK, 36 pp.

Gaines, S.D., Gaylord, B. and Largier, J.L. (2003) Avoiding current oversights in marine reserve design. Ecological Applications 13, S32-S46.
Gerber, L.R., Botsford, L.W., Hastings, A. et al. (2003) Population models for marine reserve design: a retrospective and prospective synthesis. Ecological Applications 12, S47-S64.

Gerber, L.R., Beger, M., McCarthy, M.A. and Possingham, H.P. (2005) A theory for optimal monitoring of marine reserves. Ecology Letters 8, 829-837.

Goñi, R., Quetglas, A. and Reñones, O. (2006) Spillover of spiny lobsters Palinurus elephas from a marine reserve to an adjoining fishery. Marine Ecology Progress Series $\mathbf{3 0 8}$, 207-219.

Goodman, D., Mangel, M., Parkes, G. et al. (2002) Scientific Review of the Harvest Strategy Currently Used in the BSAI and GOA Groundfish Fishery Management Plans. North Pacific Fishery Management Council, Anchorage, AK, 145 pp.

Guénette, S., Lauck, T. and Clark, C. (1998) Marine reserves: from Beverton and Holt to the present. Reviews in Fish Biology and Fisheries 8, 251-272.

Gunderson, D.R. (1997) Spatial patterns in the dynamics of slope rockfish stocks and their implications for management. Fisheries Bulletin 95, 219-230.

Halpern, B.S. (2003) The impact of marine reserves: do reserves work and does reserve size matter? Ecological Applications 12, S117-S137.

Hamel, O.S. (2005) Status and Future Prospects for the Shortspine Thornyhead Resource in Waters Off Washington, Oregon, and California as Assessed in 2005. Pacific Fishery Management Council: Stock Assessment and Fishery Evaluation Report, Portland, OR, 74 pp.

Hampton, J. and Fournier, D.A. (2001) A spatially disaggregated, length-based, age-structured population model of yellowfin tuna (Thunnus albacares) in the Western and central Pacific Ocean. Marine and Freshwater Research 52, 937-963.

Hart, D.R. (2006) When do marine reserves increase fishery yield? Canadian Journal of Fisheries and Aquatic Science 63, 1445-1449.

Hartmann, A.R. (1987) Movement of scorpionfishes (Scorpaenida: Sebastes and Scorpaena) in the Southern California Bight. California Fish and Game 73, 68-79.

Helser, T.E., Stewart, I.J., Fleisher, G. and Martell, S. (2006) Stock assessment of Pacific hake (whiting) for 2006. In: Status of the Pacific Coast Groundfish Fishery through 2005, Stock Assessment and Fishery Evaluation: Stock Assessments and Rebuilding Analyses. Pacific Fishery Management Council, Portland, Oregon, 145 pp.

Hilborn, R. and Walters, C.J. (1992) Quantitative Fisheries Stock Assessment: Choice, Dynamics and Uncertainty. Chapman \& Hall, New York.

Hilborn, R., Stokes, K., Maguire, J.J. et al. (2004) When can marine reserves improve fisheries management? Ocean and Coastal Management 47, 197-205.

Hilborn, R., Micheli, F. and DeLeo, G.A. (2006) Integrating marine protected areas with catch regulation. Canadian Journal of Fisheries and Aquatic Sciences 63, 642-649. 
Hobday, D., Punt, A.E. and Smith, D.C. (2005) Modelling the effects of marine protected areas (MPAs) on the southern rock lobster (Jasus edwardsii) fishery of Victoria, Australia. New Zealand Journal of Marine and Freshwater Research 39, 675-686.

Holland, D.S. (2002) Integrating marine protected areas into models for fishery assessment and management. Natural Resource Modeling 15, 369-386.

Holland, D.S. (2003) Integrating spatial management measures into traditional management systems: the case of the Georges Bank multispecies groundfish fishery. ICES Journal of Marine Science 60, 915-929.

Holland, D.S. (2005) Economic analysis of protection of essential fish habitat in alaskan fisheries: an analysis of research needs. US Department of Commerce, NOAA Technical Memorandum, NMFS-AFSC-154, 39 pp.

Hollowed, A.B., Bax, N., Beamish, R. et al. (2000) Are multispecies models an improvement on single-species models for measuring fishing impacts on marine ecosystems? ICES Journal of Marine Science 57, 707-719.

Jacobson, L.D. and Vetter, R.D. (1996) Bathymetric demography and niche separation of thornyhead rockfish: Sebastolobus alascanus and Sebastolobus altivelis. Canadian Journal of Fisheries and Aquatic Sciences 53, 600-609.

Jagielo, T.H. (1990) Movement of tagged lingcod (Ophiodon elongates) at Neah Bay, Washington. Fishery Bulletin $\mathbf{8 8}$, 815-820.

Jagielo, T.H. (1999) Movement, mortality, and size selectivity of sport- and trawl-caught lingcod off Washington. Transactions of the American Fisheries Society 128, 3148.

Jagielo, T.H., Hoffman, A., Tagart, J. and Zimmermann, M. (2003) Demersal groundfish densities in trawlable and untrawlable habitats off Washington: implications for the estimation of habitat bias in trawl surveys. Fishery Bulletin 101, 545-565.

Johnson, D.R., Funicelli, N.A. and Bohnsack, J.A. (1999) Effectiveness of an existing estuarine no-take fish sanctuary within the Kennedy Space Center, Florida. North American Journal of Fisheries Management 19, 436-453.

Jow, T. (1969) Results of English sole tagging off California. Pacific Marine Fisheries Commission (PMFC) Bulletin 7, 16-33.

Ketchen, K.S. and Forrester, C.R. (1966) Population dynamics of the petrale sole, Eopsetta jordani, in waters off Western Canada. Bulletin of the Fisheries Research Board of Canada 153, 195.

Kimura, D.K., Shimada, A.M. and Shaw, F.R. (1998) Stock structure and movement of tagged sablefish, Anoplopoma fimbria, in offshore northeast Pacific waters and the effects of El Niño-Southern Oscillation on migration and growth. Fishery Bulletin 96, 462-481.

Kramer, D.L. and Chapman, M.R. (1999) Implications of fish home range size and relocation for marine reserve function. Environmental Biology of Fishes 55, 65-79.
Kronlund, A.R. and Yamanaka, K.L. (2001) Yelloweye rockfish (Sebastes ruberrimus) life history parameters assessed from areas with contrasting fishing histories. In: Spatial Processes and Management of Marine Populations (Lowell-Wakefield Fisheries Symposia Series, Anchorage, October, 1999). G.H. Kruse, N. Bez, A. Booth, M.W. Dorn, S. Hills, R.N. Lipcius, D. Pelletier, C. Roy, S.J. Smith and D. Withrell, eds. University of Alaska Sea Grant Report AK-SG-01-02, Fairbanks, AK, pp. 257280.

Lea, R.N., McAllister, R.D. and VanTresca, D.A. (1999) Biological Aspects of Nearshore Rockfishes of the Genus Sebastes from Central California. Department of Fish and Game Fish Bulletin, 177 pp.

Legault, C.M. and Stone, H.H. (2004) Stock Assessment of Georges Bank (5Zhjmn) Yellowtail Flounder for 2005. Transboundary Resource Assessment Committee Reference Document 2004/03. Department of Fisheries and Oceans, Canada, 102 pp.

Levin, P.S., Holmes, E.E., Piner, K.R. and Harvey, C.J. (2006) Shifts in a Pacific ocean fish assemblage: the potential influence of exploitation. Conservation Biology 20, 1181-1190.

Love, M.S. (1981) Evidence of movements of some deepwater rockfishes (Scorpaenidae: Genus Sebastes) off Southern California. California Fish and Game 67, 246249.

Love, M.S., Axell, B., Morris, P., Collins, R. and Brooks, A. (1987) Life history and fishery of the California Scorpionfish, Scorpaena guttata, within the Southern California Bight. Fishery Bulletin 85, 99-116.

Love, M.S., Yolkavich, M. and Thorsteinson, L. (2002) The Rockfishes of the Northeast Pacific. University of California Press, Berkeley, CA.

MacCall, A.D. (2002) Fishery-management and stockrebuilding prospects under conditions of low-frequency environmental variability and species interactions. Bulletin of Marine Science 70, 613-628.

MacCall, A.D. (2003) Status of bocaccio off California in 2003. In: Appendix to the Status of the Pacific Coast Groundfish Fishery through 2003: Stock Assessment and Fishery Evaluation. Pacific Fishery Management Council, Portland, OR, $63 \mathrm{pp}$.

Mangel, M. (1998) No-take areas for sustainability of harvested species and a conservation invariant for marine reserves. Ecology Letters 1, 87-90.

Mangel, M. and Smith, P.E. (1990) Presence-absence sampling for fisheries management. Canadian Journal of Fisheries and Aquatic Sciences 47, 1875-1887.

Mangel, M., Hofman, R.J., Norse, E.A. and Twiss, J.R. (1993) Sustainability and ecological research. Ecological Applications 3, 573-575.

Martell, S.J.D., Essington, T.E., Lessard, B., Kitchell, J.F., Walters, C.J. and Boggs, C.H. (2005) Interactions of productivity, predation risk, and fishing effort in the efficacy of marine protected areas for the central Pacific. 
Canadian Journal of Fisheries and Aquatic Sciences 62, 1320-1336.

Mathews, S.B. and Barker, M.W. (1983) Movements of rockfish (Sebastes) tagged in northern Puget Sound, Washington. Fishery Bulletin 82, 916-922.

Mathews, S.B. and LaRiviere, M. (1987) Movement of tagged lingcod, Ophiodon elongates, in the Pacific Northwest. Fishery Bulletin 85, 153-159.

Matthews, K.R. (1990) An experimental study of the habitat preferences and movement patterns of copper, quillback, and brown rockfishes (Sebastes spp.). Environmental Biology of Fishes 29, 161-178.

Maunder, M.N. and Punt, A.E. (2004) Standardizing catch and effort data: a review of recent approaches. Fisheries Research 70, 141-159.

McClanahan, T.R. and Mangi, S. (2000) Spillover of exploitable fishes from a marine park and its effect on the adjacent fishery. Ecological Applications 10, 17921805.

Methot, R.D. (2000) Technical Description of the Stock Synthesis Assessment Program. US Department of Commerce, NOAA Technical Memorandum NMFS-NWFSC43, 56 pp.

Methot, R.D. (2005) User Manual for the Assessment Program Stock Synthesis 2 (SS2). Available online: http://nft.nefsc.noaa.gov/

Methot, R.D. and Stewart, I.J. (2005) Status of the U.S. canary rockfish resource in 2005. In: Status of the Pacific Coast Groundfish Fishery through 2005, Stock Assessment and Fishery Evaluation: Stock Assessments and Rebuilding Analyses. Pacific Fishery Management Council, Portland, OR, 272 pp.

Methot, R.D., Crone, P., Conser, R.J., Brodziak, J., Builder, T. and Kamikawa, D. (1999) Status of the sablefish resource off the U.S. Pacific Coast in 1998. In: Appendix to the Status of the Pacific Coast Groundfish Fishery through 1998: Stock Assessment and Fishery Evaluation. Pacific Fishery Management Council, Portland, OR, pp. 102.

Moser, H.G., Charter, R.L., Watson, W. et al. (2000) Abundance and distribution of rockfish (Sebastes) larvae in the southern California Bight in relation to environmental conditions and fishery exploitation. CalCOFI Reports 41, 132-147.

Murawski, S.A., Brown, R., Lai, H.L., Rago, P.J. and Hendrickson, L. (2000) Large-scale closed areas as a fishery-management tool in temperate marine systems: the Georges Bank experience. Bulletin of Marine Science 66, 775-798.

Murawski, S.A., Wigley, S.E., Fogarty, M.J., Rago, P.J. and Mountain, D.G. (2005) Effort distribution and catch patterns adjacent to temperate MPAs. ICES Journal of Marine Science 62, 1150-1167.

Murray, S.N., Ambrose, R.F. and Bohnsack, J.A. et al. (1999) No-take reserve networks: sustaining fishery populations and marine ecosystems. Fisheries 24, 1125.
National Research Council (NRC). (1998) Improving Fish Stock Assessments. National Academy Press, Washington, DC.

National Research Council (NRC). (2001) Marine Protected Areas: Tools for Sustaining Ocean Ecosystems. National Academy Press, Washington, DC.

National Research Council (NRC). (2006) Dynamic Changes in Marine Ecosystems: Fishing, Food Webs, and Future Options. National Academy Press, Washington, DC.

O'Connell, V.M. and Carlile, D.W. (1993) Habitat-specific density of adult yelloweye rockfish Sebastes ruberrimus in the eastern Gulf of Alaska. Fishery Bulletin 91, 304-309.

Pauly, D., Christensen, V., Guenette, S. et al. (2002) Towards sustainability in world fisheries. Nature $\mathbf{4 1 8}$, 689-695.

Pearcy, W.G. (1992) Movements of acoustically-tagged yellowtail rockfish Sebastes flavidus on Heceta Bank, Oregon. Fishery Bulletin 90, 726-735.

Pedersen, M.G. (1975) Movement and growth of petrale sole (Eopsetta jordani) tagged off Washington and southwest Vancouver Island. Journal of the Fisheries Research Board of Canada 32, 2169-2177.

Pelletier, D. and Mahevas, S. (2005) Spatially explicit fisheries simulation models for policy evaluation. Fish and Fisheries 6, 307-349.

Pikitch, E.K., Santora, C. and Babcock, E.A. et al. (2004) Ecosystem-based fishery management. Science $\mathbf{3 0 5}$, 346-347.

Punt, A.E. and Methot, R.D. (2004) Effects of marine protected areas on the assessment of marine fisheries. In: Aquatic Protected Areas as Fisheries Management Tools (American Fisheries Society Symposium 42, Quebec, Canada, 11-12 August 2003). J.B. Shipley, ed. American Fisheries Society, Bethesda, MD, pp. 133-154.

Punt, A.E., Pribac, F., Walker, T.I., Taylor, B.L. and Prince, J.D. (2000) Stock assessment of school shark Galeorhinus galeus based on a spatially-explicit population dynamics model. Marine and Freshwater Research 51, 205-220.

Punt, A.E., Smith, A.D., Davidson, A.J., Mapstone, B.M. and Davies, C.R. (2001) Evaluating the scientific benefits of spatially explicit experimental manipulations of common coral trout (Plectropomus leopardus) on the Great Barrier Reef, Australia. In: Spatial Processes and Management of Marine Populations (Lowell-Wakefield Fisheries Symposia Series, Anchorage, October, 1999), G.H. Kruse, N. Bez, A. Booth, M.W. Dorn, S. Hills, R.N. Lipcius, D. Pelletier, C. Roy, S.J. Smith and D. Withrell, eds. University of Alaska Sea Grant Report AK-SG-01-02, Fairbanks, AK, pp. 67-103.

Ralston, S. (2002) West coast groundfish harvest policy. North American Journal of Fisheries Management 22, 249 250.

Ralston, S., Bence, J.R., Eldridge, M.B. and Lenarz, W.H. (2003) An approach to estimating rockfish biomass based on larval production, with application to Sebastes jordani. Fishery Bulletin 101, 129-146. 
Richards, L.J. (1986) Depth and habitat distributions of three species of rockfish (Sebastes) in British Columbia: observation from the submersible PICES IV. Environmental Biology of Fishes 17, 13-21.

Roberts, C.M., Bohnsack, J.A., Gell, F., Hawkins, J.P. and Goodridge, R. (2001) Effects of marine reserves on adjacent fisheries. Science 294, 1920-1923.

Rogers, J. (2005) Status of the darkblotched rockfish (Sebastes crameri) resource in 2005. In: Status of the Pacific Coast Groundfish Fishery through 2005, Stock Assessment and Fishery Evaluation: Stock Assessments and Rebuilding Analyses. Pacific Fishery Management Council, Portland, OR, $121 \mathrm{pp}$.

Russ, G.R., Alcala, A.C. and Maypa, A.P. (2003) Spillover from marine reserves: the case of Naso vlamingii at Apo Island, the Philipinnes. Marine Ecology Progress Series 264, 15-20.

Salomon, A.K., Waller, N.P., McIlhagga, C., Yung, R.L. and Walters, C. (2002) Modeling the trophic effects of marine protected area zoning policies: a case study. Aquatic Ecology 36, 85-95.

Schaefer, M.B. (1954) Some aspects of the dynamics of populations important to the management of the commercial marine fisheries. Bulletin of the Inter-American Tropical Tuna Commission 1, 27-56.

Schnute, J.T. and Richards, L.J. (2001) Use and abuse of fishery models. Canadian Journal of Fisheries and Aquatic Sciences 58, 10-17.

Sladek-Nowlis, J. and Roberts, C.M. (1999) Fisheries benefits and optimal design of marine reserves. Fishery Bulletin 97, 604-616.

Stanley, R.D., Leaman, B.M., Haldorson, L. and O'Connell, V.M. (1994) Movement of tagged adult yellowtail rockfish, Sebastes flavidus, off the west coast of North America. Fisheries Bulletin 92, 655-663.

Stanley, R.D., Kieser, R., Cooke, K., Surry, A.M. and Mose, B. (2000) Estimation of a widow rockfish (Sebastes entomelas) shoal off British Columbia, Canada as a joint exercise between stock assessment staff and the fishing industry. ICES Journal of Marine Science 57, 1035-1049.

Starr, R.M., Heine, J.N. and Cailliet, G.M. (2002) Movements of bocaccio (Sebastes paucispinis) and greenspotted (S. chlorostictus) rockfishes in a Monterey submarine canyon: implications for the design of marine reserves. Fishery Bulletin 100, 324-337.

Starr, R.M., O'Connell, V. and Ralston, S. (2004) Movements of lingcod (Ophiodon elongates) in southeast Alaska: potential for increased conservation and yield from marine reserves. Canadian Journal of Fisheries and Aquatic Sciences 61, 1083-1094.

Stein, D.L., Tissot, B.N., Hixon, M.A. and Barss, W. (1992) Fish-habitat associations on a deep reef at the edge of the Oregon continental shelf. Fishery Bulletin 90, 540-551.

Stephens, A.E. and MacCall, A. (2004) A multispecies approach to subsetting logbook data for purposes of estimating CPUE. Fisheries Research 70, 299-310.
Stewart, I.J. (2005) Status of the U.S. English sole resource in 2005. In: Status of the Pacific Coast Groundfish Fishery through 2005, Stock Assessment and Fishery Evaluation: Stock Assessments and Rebuilding Analyses. Pacific Fishery Management Council, Portland, OR, $221 \mathrm{pp}$.

Wakefield, W.W. (1990) Patterns in the Distribution of Demersal Fishes on the Upper Continental Slope Off Central California with Studies on the Role of Ontogenetic Vertical Migration in Particle Flux. PhD Dissertation Scripps Institution of Oceanography, University of California San Diego, San Diego, CA, 229 pp.

Walters, C. (2003) Folly and fantasy in the analysis of spatial catch rate data. Canadian Journal of Fisheries and Aquatic Sciences 60, 1433-1436.

Walters, C., Pauly, D. and Christensen, V. (1999) Ecospace: prediction of mesoscale spatial patterns in trophic relationships of exploited ecosystems, with emphasis on the impacts of marine protected areas. Ecosystems 2 , 539-554.

Walters, C.W., Christensen, V., Martell, S.J. and Kitchell, J.F. (2005) Possible ecosystem impacts of applying MSY policies from single species assessments. ICES Journal of Marine Science 62, 558-568.

Ware, D.M. and McFarlane, G.A. (1995) Climate-induced changes in Pacific hake (Merluccius productus) abundance and pelagic community interactions in the Vancouver Island Upwelling System. In: Climate change and northern fish populations (ed. R.J. Beamish). Canadian Special Publications in Fisheries and Aquatic Sciences 121, 509-521.

Warner, R.R., Swearer, S.E. and Caselle, J.E. (2000) Larval accumulation and retention: implications for the design of marine reserves and essential fish habitat. Bulletin of Marine Science 66, 821-830.

Westrheim, S.J., Barss, W.H., Pikitch, E.K. and Quirollo, L.F. (1992) Stock delineation of Dover sole in the California-British Columbia region, based on tagging studies conducted during 1948-1979. North American Journal of Fisheries Management 12, 172-181.

Wilen, J.E. (2004) Spatial management of fisheries. Marine Resource Economics 19, 7-19.

Willis, T.J., Millar, R.B. and Babcock, R.C. (2003) Protection of exploited fish in temperate regions: high density and biomass of snapper Pagrus auratus (Sparidae) in northern New Zealand marine reserves. Journal of Applied Ecology 40, 214-227.

Yoklavich, M.M., Greene, H.G., Cailliet, G.M., Sullivan, D.E., Lea, R.N. and Love, M.S. (2000) Habitat associations of deep-water rockfishes in a submarine canyon: an example of a natural refuge. Fisheries Bulletin 98, 625-641.

Zimmermann, M. (2003) Calculation of untrawlable areas within the boundaries of a bottom trawl survey. Canadian Journal of Fisheries and Aquatic Sciences 60, 657-669. 